THE ROLE OF MINDFULNESS IN VIEWING \& MAKING ART

* This manuscript should be cited as:

Zabelina, D. L., White, R. A., Tobin, A., \& Thompson, L. (in press). The role of mindfulness in viewing and making art in children and adults. Mindfulness.

\title{
The Role of Mindfulness in Viewing and Making Art In Children and Adults.
}

\author{
Darya L. Zabelina, ${ }^{1}$ Rebecca A. White, ${ }^{2}$ Amanda Tobin ${ }^{3}$, \& Laura Thompson ${ }^{3}$ \\ ${ }^{1}$ University of Arkansas \\ ${ }^{2}$ University of New Hampshire \\ ${ }^{3}$ Massachusetts Museum of Contemporary Art
}

This research was supported in part by the Mind \& Life Institute, Francisco J. Varela Grant, 002869-00001A to DLZ.

Correspondence concerning this article should be addressed to Darya L. Zabelina, Department of Psychological Science, 480 Campus Drive, Fayetteville, AR 72701. Ph: 479-5755813. E: dlzabeli@uark.edu. 
THE ROLE OF MINDFULNESS IN VIEWING \& MAKING ART

\begin{abstract}
Objectives. Mindfulness training has been shown to have robust attentional and cognitive benefits. However, little is known about its effects on viewing and making art. Here, we explored the effects of mindfulness-based manipulation in art viewing and art making in two studies. Methods. In Study 1, elementary school children $(\mathrm{N}=59)$ participated in an art tour of the Kidspace gallery at the Massachusetts Museum of Contemporary Art (MASS MoCA), and viewed and made artworks either with or without mindfulness manipulation. In Study 2 university students $(\mathrm{N}=193)$ were randomly assigned to either the mindfulness or the control condition, and also viewed and made artworks. Results. In Study 1, elementary students who received mindfulness induction (vs. control) reported larger difference in excitement levels between the previously seen versus new artworks, expressing more excitement about the old vs. new artworks. Further, the artworks created by children in the mindfulness (vs. control) condition were rated by independent judges as more creative and more complex. In Study 2, university students who received the mindfulness (vs. control) induction reported better memory for previously seen vs. new artworks. Their own artworks were rated by independent judges as more creative, abstract, and expressive compared to the participants in the control condition.
\end{abstract} Conclusions. Together, results suggest that mindfulness-based practices may result in a deeper art viewing experience, and in personal art that is more creative and expressive in both children and adults.

Keywords: Mindfulness; viewing art; making art; memory; creativity; museums 
THE ROLE OF MINDFULNESS IN VIEWING \& MAKING ART

\section{The Role of Mindfulness in Viewing and Making Art in Children and Adults.}

Museum field trips have been shown to result in increased educational value, such as improved critical thinking skills about art, and increased empathy and tolerance about historical events (Greene et al., 2014; Kisida et al., 2016). Furthermore, people viewing art in a museum (vs. laboratory) setting report enhanced appreciation and memory of the artworks (Brieber et al., 2015; Specker et al., 2017). However, it is unclear whether current methods of conducting museum tours are maximally effective, or whether improvements can be implemented to increase their effectiveness. The majority of museum tours' methods are almost strictly information-based, where the tour guides focus on the facts about the artworks, such as a brief description about the work and the artist.

The theoretical framework guiding the present research is based on the Mirror Model of Art, which is rooted in the seminal work on aesthetic processing (Chatterjee, 2003; Leder et al., 2004; Locher et al., 2010), and suggests that art viewing and art making are not distinctly separate processes, but interface by mirroring each other (Tinio, 2013). According to the model, early stages of art viewing correspond to the late stages of art making, while late stages of art viewing correspond to the early stages of art making. Specifically, the mirror model suggests that art-making consists of three stages: Initialization, when abstract ideas are conceptualized; expansion and adaptation, when the initial structure of the artwork is developed; and finalizing, when the details of the artwork are refined. Thus initial abstract ideas are gradually transformed into a concrete artwork. Art-viewing, on the other hand, consists of the three stages that "mirror" the stages of art-making, namely: Early automatic processing, intermediate memory-based processing, and meaning-making, aesthetic judgements, and aesthetic emotions. Based on the Mirror Model of Art, viewing art and making art are inexplicably linked, thus a deeper 
THE ROLE OF MINDFULNESS IN VIEWING \& MAKING ART

engagement with the works of art during art viewing, and enhanced awareness of one's reactions and emotions to the art, enhanced by a mindfulness-based manipulation, should result in enhanced self-expression during art making experience.

Mindfulness is defined as a state of nonjudgmental, sustained, and alert awareness (Brown \& Ryan, 2003), and is suggested to be comprised of five facets, namely observing, describing, acting with awareness, non-judging, and non-reactivity (Baer et al., 2004). The observing facet of mindfulness in particular has been linked with both frequency of aesthetic experiences evoked by the art (Harrison \& Clark, 2016), and enhanced creativity during art making (Baas et al., 2014). Overall, mindfulness has recently gained significant attention and momentum in academia and popular culture (Eberth \& Sedlmeier, 2012). Mindfulness is reported to improve people's cognitive, emotional, and interpersonal functioning (Sedlmeier et al., 2012), enhance the ability to concentrate (Sedlmeier et al., 2012), decrease the fear of being judged, and reduce aversive self-conscious experience (Brown et al., 2007). The transformational effects of mindfulness are suggested to rely on three primary mechanisms: Intention, attention, and attitude (Shapiro et al., 2006). A meta-analysis of 21 neuroimaging studies of meditation practitioners (compared to people with no meditation experience) suggests that mindfulness meditation has the largest impact on the prefrontal cortex, which is implicated in coordinating and adjusting complex behaviors and impulse control (Miller \& Cohen, 2001), as well as on the body awareness regions (Fox et al., 2014). Mindfulness has also been shown to decrease functional connectivity in the default mode (DM) network both in resting state and during meditation (Brewer et al., 2011). Given that activity in the DM network is associated with taskunrelated thoughts and can compromise on-task performance (for review, Smallwood et al., 
THE ROLE OF MINDFULNESS IN VIEWING \& MAKING ART

2012), it is likely that mindfulness-based manipulations may facilitate complex activities that benefit from focused attention, including art viewing and art-making activities.

Empirical evidence points to a strong relationship between mindfulness and creativity, commonly defined by novelty and usefulness (Runco \& Jaeger, 2012). In a meta-analysis of 20 samples in studies on the link between mindfulness and creativity, a significant correlation emerged between the open-monitoring aspect of mindfulness and creativity (Lebuda et al., 2015). Mindfulness appears to impact several different features of creativity, including creative complexity (Zabelina et al., 2011), novelty of ideas (originality), and the ability to create and use new mental categories and concepts (flexibility; Colzato et al., 2012). Mindfulness-based meditation has been shown to enhance creativity regardless of the length of practice (Jedrczak et al., 1985), with even a short meditation stimulating the creative processes (Ding et al., 2014).

The enhanced ability to observe, i.e., the ability to notice and attend to various internal and external stimuli, is suggested to be the mechanism by which mindfulness facilitates creative thinking (Baas et al., 2014). The ability to observe has also been linked with reduced cognitive rigidity (Greenberg et al., 2012; Schmertz et al., 2009) and with increased cognitive flexibility (Slagter et al., 2007) - cognitive mechanisms that are at the core of creative cognition (Zabelina \& Robinson, 2010). Thus, given prior work on the link between mindfulness and both aesthetic experiences evoked by the art (Harrison \& Clark, 2016), and creativity during art making (Baas et al., 2014), and the proposed common mechanisms between the two processes (Tinio, 2013), a mindfulness manipulation should enhance both art viewing and art making experiences.

The present studies investigated whether the mindfulness manipulation impacts people's experience while viewing and making art. Specifically, we examined the effects of mindfulness on viewing art and making art in elementary school children from low socio-economic (SES) 
THE ROLE OF MINDFULNESS IN VIEWING \& MAKING ART

backgrounds (Study 1), and in young adults (Study 2). Study 1 examined the effect of

mindfulness-based instructions (vs. no mindfulness instructions) during an art gallery tour at the Massachusetts Museum of Contemporary Art (MASS MoCA) in North Adams, MA. We examined the effect of a mindfulness manipulation on children's recollection of the artworks, as well as their appreciation for the art, including their emotional valence, emotional arousal, and aesthetic preference. Given that mindfulness has also been linked with individual differences in creative output (Baas et al., 2014), and that art viewing and art making may not be distinct processes (Tinio, 2013), we examined the effect of a mindfulness manipulation in art-making activities.

\section{Study 1}

\section{Method}

\section{Participants}

Fifty-nine students from Pittsfield Morningside Elementary School ages 6-9 (mean age = 7.57, $S D=.64 ; 29$ male, 22 female, 8 unreported) participated in the study. Children's parents indicated that $35.6 \%$ of the participants identified as White/Caucasian, $15.3 \%$ as Hispanic, $6.8 \%$ as African American, 20.3\% as Multiracial, and 22\% chose not to report this information. Participants were recruited by the museum staff, as none of the students from this school have previously participated in the MASS MoCA art tours. All recruited students accepted to participate. Students' parents completed the consent form prior to the students' participation in the study. The study was approved by the local Institutional Review Board (IRB).

\section{Procedure}

Over two days, four tours took place - two on each day, employing a between-group design. The first tour group on each day was assigned as the mindfulness condition $(n=29)$, 
THE ROLE OF MINDFULNESS IN VIEWING \& MAKING ART

which received the mindfulness manipulation, and the second tour group was assigned as the control condition $(n=30)$, which did not receive the mindfulness manipulation. All groups participated in the guided gallery tour, art making activities, and completed the Qualtrics questionnaire. Data collection through Qualtrics failed for the first mindfulness group $(n=12)$, therefore children's art-viewing experience ratings include 17 participants in the mindfulness condition, and 30 participants in the control condition. Children's artworks during art-making activities were collected for all 59 participants, and were rated by independent judges blind to the condition or to the purpose of the study.

After arriving at the museum, children took part in the gallery tour (45 minutes), then were either involved in the mindfulness manipulation (10 minutes), or went directly to the art making activity (control group). After creating their artworks (15 minutes), each group completed the Qualtrics questionnaire on iPads/tablets and answered questions about 8 artworks that they saw during the tour, and 8 new artworks that they did not see during the tour (10 minutes). Once all of the questionnaires were completed and the iPads/tablets were collected, children were thanked for their participation and given a small gift. The entire session lasted approximately 80 minutes.

Upon arriving at MASS MoCA, the groups were introduced to their tour guide, and were told the story of The Blind Man and the Elephant (Thompson \& Tobin, 2018). The tour guide informed the group that the tour would be about problem-solving using the five senses, just like the blind man in the story. They were then asked to recall what the five senses were. The guide explained that this story, as well as the exhibition they were about to see, reveals that there were many different ways to solve a problem, or view a work of art. 
THE ROLE OF MINDFULNESS IN VIEWING \& MAKING ART

All groups were taken through the same portions of the exhibit in the same order, and focused on the same concepts. There were three individual portions of Kidspace included in the tour, referred to as "Chains" - "Freedom," "Love," and "Sadness." The Chains contain artworks which were intended to represent the concept for which they were named. The catalyst for each Chain was a painting by local elementary students, which were used as direct inspiration for an artwork by a professional artist, and then these artworks were also used as inspiration by other professional artists, forming a Chain.

For example, at the beginning of the Freedom Chain, the tour guide asked the group: "If you were going to express this painting as a sound, what would it be?" After responding, the group listened to a song created by a musician who used the student's painting as inspiration. While walking through each Chain, participants were asked questions such as "Take a moment to look at the different works of art. What do they have in common? What is different about them?" and "What do you notice about the wall itself? How does it connect (or not connect) to the art?" Same questions were asked in each Chain and in all groups. Children were not informed that later they would be asked questions about the artworks.

Mindfulness manipulation. Upon completion of the tour, participants in the mindfulness condition received the mindfulness induction. They were asked to sit at tables in the exhibit hall and reflect back on ways that they experienced the exhibition tour using four of the five senses: taste, touch, smell, and sight. Then, they were asked to partake in a mindfulness activity - a slow eating experience. The guide passed around a bowl of Craisins, instructing children to each take one. Children were told they did not have to eat the Craisin if they did not like it (none of the children chose not to partake in this activity). The mindfulness manipulation began with the children closing their eyes and taking a deep breath. They were told to hold the Craisin in their 
THE ROLE OF MINDFULNESS IN VIEWING \& MAKING ART

hand and report what it felt like after running their finger over it, squeezing it, etc. Was is it bumpy or smooth? Hard or soft? Where were the wrinkles? They were then asked to smell it, and report what they smelled. They were then instructed to open their eyes and study the Craisin. The tour guide asked them questions such as: "What do you notice about the texture?", "What happens when light hits it?" and "What colors can you see?" After closing their eyes once again and taking another deep breath, children were told about the origins of the Craisin, with instructions to visualize each part of the process. Children were told that this Craisin arrived here after being purchased from a store, the store bought the Craisins from a processing plant, someone first had to harvest the cranberries, and water and sunlight had to nurture their growth. This concluded with the statement: "So you are holding in your hands the product of many people's work, as well as many different rains, rays of sunshine, and types of soil, all of which had to come together for you to eat this Craisin."

The mindfulness instruction concluded with the children being told that they can eat the Craisin, but not to swallow it right away - rather, to place the Craisin on their tongue and keep it there for 10 seconds. They were asked to report: "What does it feel like on your tongue?" and "What flavors can you taste if you hold the Craisin at the front of your mouth? At the back?". The guide then told the children to take one bite and report how the flavor changed. In order to prolong the taste sensation, they were asked to slowly chew the Craisin 10 times before swallowing. Lastly, they reported what kinds of flavors lingered on their tongue after swallowing.

Art making. Both groups interpreted their experience that day through creating their own work of art. First, the tour guide performed a demonstration to illustrate how to use abstract concepts such as lines to represent emotions. In front of the group, the guide painted a 
THE ROLE OF MINDFULNESS IN VIEWING \& MAKING ART

sloping blue line and then asked the group what kind of emotion the line, color, or the way it was painted reminded them of and why. This was repeated once or twice with different types of lines (e.g., a red, jagged line to represent anger, a yellow, bouncy line to represent joy) until the entire group was clear regarding the instructions. Children were then asked to create their own work of art and were allowed to paint anything they pleased.

\section{Measures}

Five raters blind to the condition and the purpose of the investigation (all female, mean age $=20.2, S D=1.7$, all undergraduate psychology students) rated children's artworks on the following dimensions (Likert scale $1=$ not at all, 5 = very much): Creative (inter-rater reliability $\alpha=.84$ ), complex (inter-rater reliability $\alpha=.83$ ), abstract (inter-rater reliability $\alpha=$ .80 ), expressive (inter-rater reliability $\alpha=.79$ ), positive (inter-rater reliability $\alpha=.91$ ), and negative (inter-rater reliability $\alpha=.91$ ). The items were developed based on prior work on the link between mindfulness and creativity (Baas et al., 2014; Zabelina et al., 2011). We included an additional item of abstractness given the abstract nature of the art-making activity.

Art-viewing questionnaire. The Art Viewing Questionnaire was presented to the participants as “The Art Game," and intended to measure children's memory and experiences during art viewing. Participants completed one practice trial, which was identical in structure to the real trials, but did not count towards the overall score. Each trial consisted of a photo of an artwork that the students either saw during the tour, or a new, previously not seen artwork, followed by a series of questions. The previously seen and the new artworks were randomized for each participant. Responses were given on a continuous scale ranging from 1-10. The four items were developed based on the items from past work (Brieber et al., 2015). Dependent variables were: (1) Recollection ("Did you see this picture today?" with anchors No, I don't 
THE ROLE OF MINDFULNESS IN VIEWING \& MAKING ART

know, Yes), (2) emotional valence ("How does this picture make you feel?" with anchors Sad,

Neutral, Happy), emotional arousal ("Is this picture boring, neutral, or exciting?" with anchors Boring, Neutral, Exciting), and aesthetic preference ("Do you like this picture?" with anchors No, Not sure, Yes). There were 16 total trials, with 8 seen and 8 new photos of the artworks. Participants responded at their own pace (presentation of the artworks was not timed).

Data analysis. First, we performed two $2 \times 2$ repeated-measure analyses of variance (ANOVA) to test the effect of mindfulness on children's' art-viewing experience. For both analyses, condition (mindfulness vs. control) was the between-subject variable. For the first analysis, memory ratings of the previously seen and new artworks was the within-subject variable, and for the second analysis, excitement ratings for the previously seen and new artworks was the within-subject variable. Following this, we performed separate between-subject ANOVAs to test the effect of mindfulness on children's art-making activities, while controlling for age, as children's art-making abilities have been found to vary greatly with age (Picard \& Gauthier, 2012).

\section{Results}

\section{Art-Viewing: Children's Ratings of the Previously Seen and New Artworks}

The first $2 \times 2$ ANOVA indicated that there was a main effect of memory, $F(1,45)=$ $582.84, p<.001, \eta^{2}=.93$, indicating that overall children were more likely to say that they remembered seeing previously seen artworks $(M=8.09, S E=.22)$ compared to the new artworks $(M=.95, S E=.18)$. There was no main effect of condition, $F(1,45)=2.73, p=.11, \eta^{2}=.06$, and no condition x memory interaction, $F(1,45)<1$.

The second $2 \times 2$ ANOVA indicated that there was a main effect of excitement, $F(1,45)=$ $24.09, p<.001, \eta^{2}=.35$, showing that overall children were more excited about the previously 
THE ROLE OF MINDFULNESS IN VIEWING \& MAKING ART

seen artworks $(M=6.37, S E=2.02)$ compared to the new artworks $(M=5.15, S E=2.32)$. There was no main effect of condition, $F(1,45)=1.02, p=.32, \eta^{2}=.02$. As predicted, there was a significant condition $\mathrm{x}$ excitement interaction, $F(1,45)=4.76, p=.03, \eta^{2}=.10$. Specifically, in the mindfulness condition there was a larger difference in excitement levels between the previously seen $(M=6.38, S E=.50)$ and the new artworks $(M=4.37, S E=.55), p<.001$, than in the control condition for previously seen $(M=6.36, S E=.37)$ and new artworks $(M=5.59, S E$ $=.41), p=.03$ (Figure 1). These results suggest that children in the mindfulness condition found new artworks less emotionally arousing than the previously seen artworks, while children in the control condition showed similar emotional arousal levels for the previously seen and the new artworks.

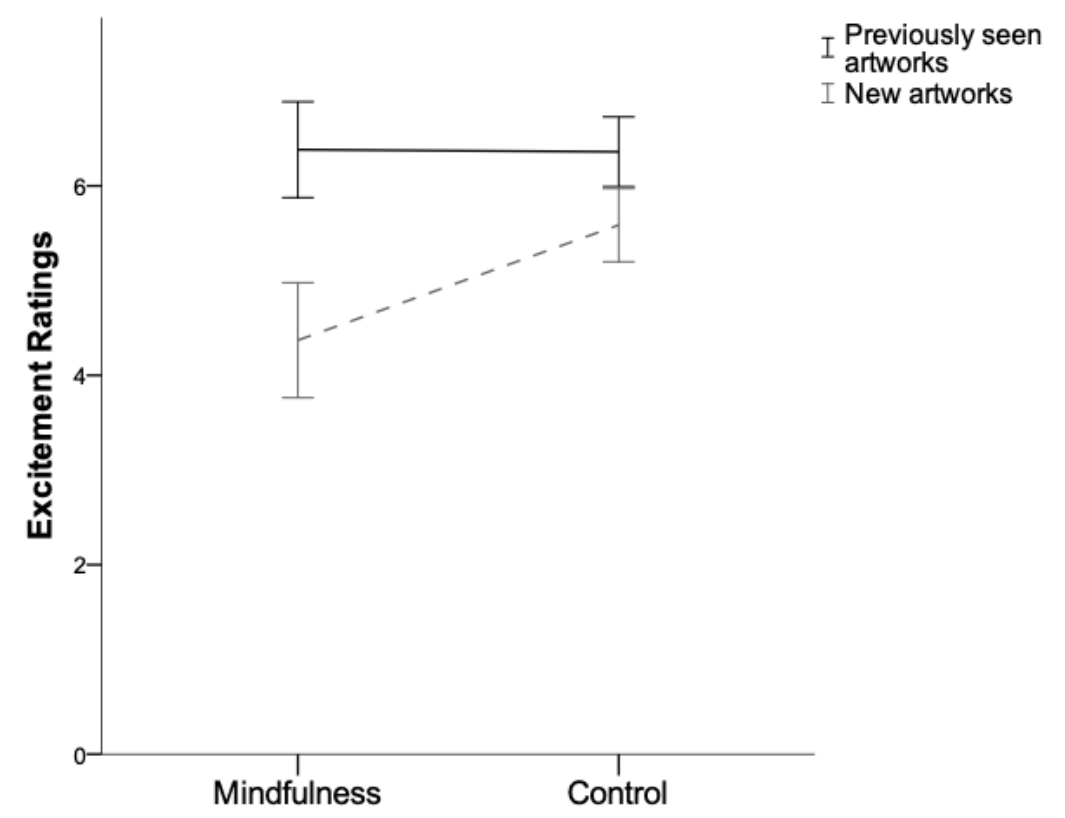

Figure 1. Children's Reports of Excitement About Previously Seen and New Artworks as a Function of Experimental Condition (Mindfulness vs. Control). Error bars represent standard error. 
THE ROLE OF MINDFULNESS IN VIEWING \& MAKING ART

\section{Art-Making: Children's Drawings}

A between-subject ANOVA, controlling for age, indicated that, as predicted, children's drawings in the mindfulness condition were judged as more creative, more complex, and marginally more expressive. Children's drawings in the mindfulness and control conditions did not differ in their abstractness, nor in positive or negative valence, $p \mathrm{~s}>.10$ (Table 1 , see Appendix for examples).

\section{Table 1}

Ratings of Children's Drawings as a Function of Experimental Condition, Controlling for Age (Estimated Marginal Means, $N=59$ ).

\begin{tabular}{llllll}
\hline & Mindfulness Condition & Control Condition & & & \\
& M (SE) & M (SE) & $F$ & $p$ & $\eta^{2}$ \\
\hline Creative & $3.18(.18)$ & $2.57(.18)$ & 5.78 & .02 & .11 \\
Complex & $2.60(.20)$ & $1.98(.20)$ & 4.84 & .03 & .09 \\
Abstract & $3.64(.18)$ & $3.65(.19)$ & .01 & .97 & .001 \\
Expressive & $2.92(.19)$ & $2.41(.19)$ & 3.68 & .06 & .07 \\
Positive & $2.17(.25)$ & $2.62(.25)$ & 1.68 & .20 & .03 \\
Negative & $2.94(.25)$ & $2.34(.26)$ & 2.79 & .10 & .06 \\
\hline
\end{tabular}

\section{Discussion}

Study 1 examined whether mindfulness induction would benefit elementary-school children in their art viewing experience and art-making activities. We found that after the gallery tour, children who received the mindfulness manipulation (vs. control group) exhibited a larger difference in excitement levels between the previously seen versus new artworks, expressing 
THE ROLE OF MINDFULNESS IN VIEWING \& MAKING ART

more excitement about the old vs. new artworks. This finding is especially interesting considering that the mindfulness manipulation occurred after art viewing, suggesting that mindfulness may play a role in recollection of art. An enhanced memory retention is a likely mechanism for this effect, as previous work has shown that mindfulness can enhance encoding of long-term memories (Brown, Goodman, Ryan, Anālayo, 2016; Lykins, Baer, \& Gottlob, 2012). Here we did not find that children in the mindfulness (vs. control) condition recalled seeing more artworks, although this result could be due to the ceiling effect, as children only saw a total of 8 artworks during the gallery tour, and all children easily distinguished between previously seen and new artworks.

The drawings created by children in the mindfulness (vs. control) condition were rated as more creative, more complex, and marginally more expressive compared to the children's drawings in the control condition. These results are novel in that they present findings suggesting that a short mindfulness induction can enhance emotional arousal for the previously viewed artworks, as well as enhance creativity and complexity of personally created art in elementary school-age children. Study 1 had high ecological validity as the study was conducted directly at the museum, without changing any of the procedures typically employed by the MASS MoCA staff. The tradeoff to ecological validity, however, was reduced experimental control, which was established in Study 2.

Study 1 had a few other limitations. Because the mindfulness manipulation occurred after the gallery tour (but before art-making activity), it was not possible to test the direct effects of the mindfulness manipulation in memory for the artworks. Furthermore, the control condition did not provide a control manipulation, which can be problematic. Additionally, in keeping with high ecological validity, participants were assigned to the mindfulness versus control conditions 
THE ROLE OF MINDFULNESS IN VIEWING \& MAKING ART

depending on which class they were in during the museum tour. The sample size was small, especially considering the technical issues that occurred during the first group's gallery visit. Finally, the study was not double-blind, with guides potentially more enthusiastic in the mindfulness condition, leading to differences between groups in art viewing and art making.

Study 2 was designed to address these limitations. University students $(N=193)$ were invited to participate, and were randomly assigned to either the mindfulness or the control condition. The procedure was identical in both conditions. Participants first listened to a narrated audio: In the mindfulness condition participants heard and followed instructions for a slow Craisin-eating exercise, while the control group heard an audio about glaciers in the Yosemite National Park, while also consuming a Craisin. After listening to the audio, participants viewed a slideshow of the artworks from the local art museum (set 1 or set 2, 100 artworks each), but were not informed that there would be a memory and a rating test later in the session. They then were given 5 minutes to draw a picture expressing their thoughts and feelings they experienced when viewing the artworks. Finally, they completed a surprise memory and rating task, with 25 randomly selected artworks previously seen during the slideshow, and 25 new artworks. We expected that participants in the mindfulness (vs. control) condition would remember more of the previously seen (vs. new) artworks, and would express higher emotional arousal for the previously seen (vs. new) artworks, replicating results of Study 1. Further, we expected to find that drawings produced by participants in the mindfulness (vs. control) group would be rated by independent judges as more creative, more complex, and more expressive. 
THE ROLE OF MINDFULNESS IN VIEWING \& MAKING ART

\section{Study 2}

\section{Methods}

\section{Participants}

Undergraduate students $(N=193$, mean age $=19.39, S D=1.18 ; 101$ male, 89 female, 3 other) participated in the study in return for research credit in their General Psychology courses. The majority (95\%) of participants self-identified as White/Caucasian. The study was approved by the local IRB, and all participants signed an informed consent form prior to participating. The study was a between-subject design, with participants randomly assigned to receive the mindfulness $(n=95)$ or the control manipulation $(n=98)$.

\section{Procedure}

Using the random number generator, participants were randomly assigned to either the mindfulness or the control condition, and were tested up to 8 participants at a time. Upon arrival, participants first took part in the mindfulness or the control induction ( 3 minutes), and were then randomly assigned to view either Set 1 or Set 2 of the art-viewing slideshow (10 minutes). They then engaged in the art making activity, and finally completed the surprise art-viewing questionnaire. The entire session lasted approximately 30 minutes.

\section{Measures}

Mindfulness manipulation. The manipulation was pre-recorded with a female voice using a transcription of the same slow-eating Craisin exercise that the children received in Study 1, lasting approximately 3 minutes.

Control manipulation. The control manipulation was also pre-recorded and featured the same female voice as the mindfulness manipulation. The recording included affectively neutral information regarding glaciers (i.e. how they form and travel) and valleys which were formed by 
THE ROLE OF MINDFULNESS IN VIEWING \& MAKING ART

them at the Yosemite Valley in Yosemite National Park, California, and lasted approximately 3 minutes.

Art-viewing slideshow. Two-hundred artworks from the Crystal Bridges Museum of American Art were photographed and separated into two sets of 100 photographs each. The photographs in each set were matched by a professional artist with 8 years of experience to be as similar as possible based on the content and style of the artworks in a face-valid way. Each photo was displayed for 1.5 seconds in a slideshow presented through the Qualtrics platform.

Participants were not informed that they would later be asked to recall and asked questions about the artworks.

Art making. Participants were given a box of 24 colored pencils and a blank piece of paper, and were asked to create a drawing based on the feelings they experienced while viewing the artworks. They had 5 minutes to create their drawing. One rater blind to the condition and the purpose of the investigation (female, age 22, undergraduate psychology student) rated participants' artworks on the same dimensions as in Study 1 (creative, complex, abstract, expressive, positive, negative).

Art viewing questionnaire. Twenty-five photographs from each set were randomly selected to create a "testing set" questionnaire. This questionnaire was similar to the questionnaire in Study 1, intending to measure participants' memory for and experiences regarding the artworks. Participants completed one practice trial, which was identical in structure to the real trials, but did not count toward the overall score. Each trial contained a photograph of a painting that participants saw during the Art Viewing Slideshow or a new artwork, followed by four questions. Responses were given on a continuous scale ranging from $1-10$. Dependent variables were: (1) Memory ("Did you see this picture during the viewing part of this study?" 
THE ROLE OF MINDFULNESS IN VIEWING \& MAKING ART

with anchors No, I don't know, Yes), (2) emotional valence ("How does this picture make you feel?" with anchors Sad, Neutral, Happy), emotional arousal ("Is this picture boring, neutral, or exciting?" with anchors Boring, Neutral, Exciting), and aesthetic preference ("Do you like this picture?" with anchors No, Not sure, Yes). There was an error in recording data for the aesthetic preferences ratings, thus these data are not reported here. There were 50 total trials, with 25 seen and 25 new artworks, presented in random order. Participants responded at their own pace.

Data analysis. We performed three $2 \times 2$ repeated-measure ANOVAs to test the effect of mindfulness on art-viewing experience. For all analyses, condition (mindfulness vs. control) was the between-subject variable. For the first analysis, memory (previously seen vs. new artworks) was the within-subject variable. For the second analysis, excitement ratings of the previously seen and new artworks was the within-subject variable, and for the third analysis, emotional valence ratings of the previously seen and new artworks was the within-subject variable. We also performed separate between-subject ANOVAs to test the effect of mindfulness on participants' art-making activities, while controlling for age.

\section{Results}

\section{Art-Viewing: Participants' Ratings of the Previously Seen and New Artworks}

The first 2 × 2 ANOVA indicated that there was a significant main effect of memory participants were more likely to say that they remembered seeing previously seen artworks $(M=$ $5.96, S E=.12)$ compared to the new artworks $(M=3.01, S E=.12), F(1,192)=222.49, p<.001$, $\eta^{2}=.54$. There was no main effect of condition, $F<1$.

As predicted, there was a condition $\mathrm{x}$ memory interaction, $F(1,192)=9.20, p=.003, \eta^{2}$ $=.05$. Specifically, in the mindfulness condition there was a larger difference in excitement levels between the previously seen $(M=6.21, S E=.18)$ and the new artworks $(M=2.66, S E=$ 
THE ROLE OF MINDFULNESS IN VIEWING \& MAKING ART

$.17), p<.001$ than in the control condition for previously seen $(M=5.71, S E=.18)$ and new $\operatorname{artworks}(M=3.36, S E=.17), p<.001$ (Figure2).



Figure 2. Participants' Memory Ratings of the Previously Seen and New Artworks as a Function of Experimental Condition (Mindfulness vs. Control). Error bars represent standard error.

The second $2 \times 2$ ANOVA indicated that there was a main effect of excitement, as all participants rated previously seen artworks as more exciting $(M=5.27, S E=.07)$ compared to the new artworks $(M=5.13, S E=.07), F(1,192)=6.12, p=.01, \eta^{2}=.03$. There was no main effect of condition, $F<1$, or excitement x condition interaction, $F<1$.

Finally, the third $2 \times 2$ ANOVA indicated that there was a main effect of emotional valence, as all participants indicated elevated feelings of happiness when viewing previously seen artworks $(M=5.13, S E=.05)$ compared to the new artworks $(M=4.97, \mathrm{SE}=.05), F(1,192)$ $=12.36, p=.001, \eta^{2}=.06$. There was no main effect of condition, $F<1$, or emotional valence $\mathrm{x}$ condition interaction, $F<1$. 
THE ROLE OF MINDFULNESS IN VIEWING \& MAKING ART

\section{Art-Making: Participants' Drawings}

A between-subject ANOVA indicated that, controlling for age, participants' drawings in the mindfulness condition were judged as more creative, more abstract, and more expressive than participants' drawings in the control condition, replicating results of Study 1 (Table 2). Participants' drawings in the mindfulness and control conditions did not differ in their complexity, nor in their positive or negative valence.

\section{Table 2}

Ratings of Participants' Artworks as a Function of Experimental Condition, Controlling for Age (Estimated Marginal Means, $N=193$ ).

\begin{tabular}{llllll}
\hline & Mindfulness Condition & \multicolumn{2}{l}{ Control Condition } & & \\
& M (SE) & M (SE) & $F$ & $p$ & $\eta^{2}$ \\
\hline Creative & $2.45(.12)$ & $2.00(.12)$ & 6.96 & .009 & .04 \\
Complex & $2.30(.12)$ & $2.22(.12)$ & .22 & .64 & .001 \\
Abstract & $3.33(.17)$ & $2.68(.17)$ & 7.38 & .007 & .04 \\
Expressive & $2.45(.12)$ & $2.00(.12)$ & 7.34 & .007 & .04 \\
Positive & $2.12(.13)$ & $2.03(.13)$ & .23 & .64 & .001 \\
Negative & $1.65(.12)$ & $1.68(.11)$ & .04 & .84 & .001 \\
\hline
\end{tabular}

\section{Discussion}

Study 2 examined the role of mindfulness in art-viewing and art-making activities in young adults. As predicted, we found a significant effect of mindfulness on people's memory. Specifically, young adults in the mindfulness (vs. control) condition indicated that they recall more of the previously seen (vs. new) artworks. This result likely differs from Study 1 because 
THE ROLE OF MINDFULNESS IN VIEWING \& MAKING ART

here participants saw 100 artworks, while only 8 artworks were shown during art viewing in

Study 1, likely resulting in a ceiling effect for memory. Furthermore, we found that young adults in the mindfulness (vs. control) condition created their own art that was more creative and more expressive, replicated results of Study 1.

\section{General Discussion}

Here we examined whether a mindfulness induction would benefit peoples' art viewing experience and art-making activities. According to the Mirror Model of Art, the process of art viewing and art making involve common mechanisms (Tinio, 2013), thus a mindfulness manipulation should have an impact on both processes. Indeed, in Study 1, children who received the mindfulness manipulation (vs. control) after viewing the artworks showed larger differences in excitement levels between the previously seen versus new artwork, expressing more excitement about the old vs. new artworks. Although we did not find a direct effect of mindfulness on the recall of the previously seen artworks, likely due to the ceiling effect, our results are in line with previous literature showing that mindfulness is linked with aesthetic preferences (Harrison \& Clark, 2016) and enhanced encoding of long-term memories (Brown et al., 2016; Lykins et al., 2012), further corroborating previous work on familiarity bias (Eidelman \& Crandall, 2012). Future work will need to examine these findings further.

Study 2 found that young adults who received the mindfulness manipulation (vs. control) prior to viewing the artworks showed increased memory for the previously seen (vs. new) artworks. Previously mindfulness has been shown to increase autobiographical memory specificity, and improve cognitive flexibility (Heeren et al., 2009), hence memory formation is likely the primary mechanism that resulted in increased recall of the previously seen (vs. new) artworks in the mindfulness condition. 
THE ROLE OF MINDFULNESS IN VIEWING \& MAKING ART

Mindfulness had also enhanced participants' art-making experiences in both studies. Specifically, children in Study 1 created artworks that were judged as more creative and more complex, and marginally more expressive. The creativity and the expressiveness results were replicated in Study 2. These results are in line with previous literature, which showed that mindfulness and meditation training can enhance creative performance (Ding et al., 2015; Ding et al., 2014; Ostafin \& Kassman, 2012; Ren et al., 2011). Furthermore, mindfulness can decrease the fear of being judged, and reduce aversive self-conscious experience (Brown et al., 2007), which may be the mechanisms for increased freedom of self-expression, resulting in enhanced expressiveness in participants in the mindfulness condition.

Mindfulness appears to impact several different aspects of creativity, including creative complexity (Zabelina et al., 2011), which supports the finding of Study 1 in which the artworks created by children in the mindfulness (vs. control) condition were rated as higher in complexity. The effect of mindfulness on complexity may only become evident with increased time, however, as mindfulness manipulation during the 5-minute art-making activity in Study 2 did not result in higher complexity of participants' drawings, while it did in a 15-minute art-making activity in Study 1). The effect of mindfulness on complexity during art-making as a function of time is a worthwhile endeavor for future studies.

\section{Limitations and Future Directions}

The memory and excitement results likely differ in the two studies because of the differences in the experimental manipulation. In Study 1, mindfulness induction was administered after the art viewing tour, thus examining the effects of mindfulness in memory retention. In Study 2 mindfulness induction was administered before art viewing, thus examining the effects of mindfulness on memory formation. Future studies will need to systematically test 
THE ROLE OF MINDFULNESS IN VIEWING \& MAKING ART

the effects of the mindfulness induction on both memory retention and long-term memory encoding incorporating larger sample sizes in studies with high ecological validity.

There were several other methodological differences in the two studies, e.g., mindfulness before and after art viewing, number of artworks viewed, age of the participants, and real-world vs. laboratory experimental setting. Nevertheless, across both studies we found that a mindfulness manipulation had an effect on participants' art-viewing experiences, as well as on their art-making activities, with the more creative and more expressive art -making replicating across the two studies. This replication likely speaks to the robustness of the effect.

Psychometric validity and reliability information was not available for the Art Viewing Questionnaire. Finally, the Craisin-eating mindfulness manipulation employed in the present studies may be especially well-suited for art-viewing and art-making investigations, because it encourages participants to draw their attention and become aware of a number of senses (touch, sight, smell, taste). Notwithstanding, future studies will need to test whether art viewing and art making are enhanced with other mindfulness-based manipulations (e.g., breath-focused exercises). 
THE ROLE OF MINDFULNESS IN VIEWING \& MAKING ART

\section{Conflict of Interest Statement}

The authors declare that they have no conflict of interest.

\section{Ethics Statement}

These studies have been approved by the University of Arkansas ethics committee and have therefore been performed in accordance with the ethical standards laid down in the 1964 Declaration of Helsinki and its later amendments.

\section{Informed Consent Statement}

All participants gave their informed consent prior to their inclusion in the study.

\section{Author Contribution}

DLZ: designed the study, performed data analysis, and wrote the paper. RAW: Executed the study and wrote part of the Introduction, Methods, and the Discussion sections. AT and LT designed the mindfulness manipulation, assisted in data collection, and revised the manuscript. All authors approved the final version of the manuscript for submission. 
THE ROLE OF MINDFULNESS IN VIEWING \& MAKING ART

\section{References}

Baas, M., Nevicka, B., \& Ten Velden, F. S. (2014). Specific mindfulness skills differentially predict creative performance. Personality and Social Psychology Bulletin, 40(9), 10921106.

Baer, R.A., Smith, G.T., Hopkins, J., Krietemeyer, J., \& Toney, L. (2006). Using self-report assessment methods to explore facets of mindfulness. Assessment, 13, 27-45.

Brieber, D., Nadal, M., \& Leder, H. (2015). In the white cube: Museum context enhances the valuation and memory of art. Acta Psychologica, 154, 36-42.

Brown, K. W., Goodman, R. J., Ryan, R. M., \& Anālayo, B. (2016). Correction: Mindfulness enhances episodic memory performance: Evidence from a multimethod investigation. Plos One, 11(7).

Brown, K.W., \& Ryan, R.M. (2003). The benefits of being present: Mindfulness and its role in psychological well-being. Journal of Personality and Social Psychology, 84, 822-848.

Brown, K.W., Ryan, R.M., \& Creswell, J.D. (2007). Mindfulness: Theoretical foundations and evidence for its salutary effects. Psychological Inquiry, 18, 211-237.

Chambers, R., Lo, B. C., \& Allen, N. B. (2007). The impact of intensive mindfulness training on attentional control, cognitive style, and affect. Cognitive Therapy and Research, 32(3), 303-322.

Chatterjee, A. (2003). Prospects for a cognitive neuroscience of visual aesthetics. Bulletin of Psychology and the Arts, 4, 55-60.

Colzato, L. S., Ozturk, A., \& Hommel, B. (2012). Meditate to create: The impact of focusedattention and open-monitoring training on convergent and divergent thinking. Frontiers in Psychology, 3. 
THE ROLE OF MINDFULNESS IN VIEWING \& MAKING ART

Ding, X., Tang, Y., Deng, Y., Tang, R., \& Posner, M. I. (2015). Mood and personality predict improvement in creativity due to meditation training. Learning and Individual Differences, 37, 217-221.

Ding, X., Tang, Y., Tang, R., \& Posner, M. I. (2014). Improving creativity performance by shortterm meditation. Behavioral and Brain Functions, 10(1), 9.

Eberth, J., \& Sedlmeier, P. (2012). The effects of mindfulness meditation: A meta-analysis. Mindfulness, 3(3), 174-189.

Eidelman, S., \& Crandall, C. S. (2012). Bias in favor of the status quo. Social and Personality Psychology Compass, 6(3), 270-281.

Fox, K. C., Nijeboer, S., Dixon, M. L., Floman, J. L., Ellamil, M., Rumak, S. P., . . Christoff, K. (2014). Is meditation associated with altered brain structure? A systematic review and meta-analysis of morphometric neuroimaging in meditation practitioners. Neuroscience \& Biobehavioral Reviews, 43, 48-73.

Greenberg, J., Reiner, K., \& Meiran, N. (2012). “Mind the trap": Mindfulness practice reduces cognitive rigidity. PLoS ONE, 7(5), e36206.

Greene, J.P. \& Kisida, B \& Bowen, D. (2014). Value of field trips. Taking students to an arts museum improves critical thinking skills, and more. Education Next, 14, 79-86.

Harrison, N. R., \& Clark, D. P. (2016). The observing facet of trait mindfulness predicts frequency of aesthetic experiences evoked by the arts. Mindfulness, 7(4), 971-978.

Jedrczak, E., Beresford, M., \& Clements, G. (1985). The TM-Sidhi program, pure consciousness, creativity and intelligence. The Journal of Creative Behavior, 19, 270-275. 
THE ROLE OF MINDFULNESS IN VIEWING \& MAKING ART

Kisida, B., Bowen, D. H., \& Greene, J. P. (2016). Measuring critical thinking: Results from an art museum field trip experiment. Journal of Research on Educational Effectiveness, $9(1), 171-182$.

Lebuda, I., Zabelina, D. L., \& Karwowski, M. (2015). Mind full of ideas: A meta-analysis of the mindfulness-creativity link. Personality and Individual Differences, 93, 22-26.

Leder, H., Belke, B., Oeberst, A., \& Augustin, D. (2004). A model of aesthetic appreciation and aesthetic judgments. British Journal of Psychology, 95, 489-508.

Locher, P., Overbeeke, K., \& Wensveen, S. (2010). Aesthetic interaction: A framework. Design Issues, 26, 70-79.

Lykins, E. L. B., Baer, R. A., \& Gottlob, L. R. (2012). Performance-based tests of attention and memory in long-term mindfulness meditators and demographically matched nonmeditators. Cognitive Therapy and Research, 36(1), 103-114.

Miller, E. K., \& Cohen, J. D. (2001). An integrative theory of prefrontal cortex function. Annual Review of Neuroscience, 24, 167-202.

Ostafin, B. D., \& Kassman, K. T. (2012). Stepping out of history: Mindfulness improves insight problem solving. Consciousness and Cognition, 21(2), 1031-1036.

Picard, D., \& Gauthier, C. (2012). The development of expressive drawing abilities during childhood and into adolescence. Child Development Research, 2012, 1-7.

Runco, M. A., \& Jaeger, G. J. (2012). The standard definition of creativity. Creativity Research Journal, 24(1), 92-96.

Schmertz, S. K., Anderson, P. L., \& Robins, D. L. (2009). The relation between self-report mindfulness and performance on tasks of sustained attention. Journal of Psychopathology and Behavioral Assessment, 31, 60-66. 
THE ROLE OF MINDFULNESS IN VIEWING \& MAKING ART

Sedlmeier, P., Eberth, J., Schwarz, M., Zimmermann, D., Haarig, F., Jaeger, S., \& Kunze, S. (2012). The psychological effects of meditation: A meta-analysis. Psychological Bulletin, $138,1139-1171$.

Shapiro, S. L., Carlson, L. E., Astin, J. A., \& Freedman, B. (2006). Mechanisms of mindfulness. Journal of Clinical Psychology, 62(3), 373-386.

Slagter, H. A., Lutz, A., Greischar, L. L., Francis, A. D., Nieuwenhuis, S., Davis, J. M., \& Davidson, R. J. (2007). Mental training affects distribution of limited brain resources. PLoS Biology, 5(6), e138.

Specker, E., Tinio, P. P., \& van Elk, M. (2017). Do you see what I see? An investigation of the aesthetic experience in the laboratory and museum. Psychology of Aesthetics, Creativity, and the Arts, 11(3), 265.

Thompson, L. D., \& Tobin, A. (2018). ArtInSight: A contemplative approach to museum gallery teaching and learning. Journal of Museum Education, 43(4), 334-341.

Zabelina, D. L., \& Robinson, M. D. (2010). Creativity as flexible cognitive control. Psychology of Aesthetics, Creativity, and the Arts, 4(3), 136-143.

Zabelina, D. L., Robinson, M. D., Ostafin, B. D., \& Council, J. R. (2011). Manipulating mindfulness benefits creative elaboration at high levels of neuroticism. Empirical Studies of the Arts, 29(2), 243-255. 